\title{
VERSATILE MEDIA TO REMEDIATE SITES CONTAMINATED BY CHROMIUM USING A SYSTEM OF PERMEABLE REACTIVE BARRIERS
}

\author{
L. N. ANDRADE ${ }^{1}$, P. R. FRADE ${ }^{1}$, C. C. AMORIM ${ }^{1 *}$ e M. M. D. LEÃO ${ }^{1}$ \\ ${ }^{1}$ Universidade Federal de Minas Gerais, Departamento de Engenharia Sanitária e Ambiental \\ *E-mail para contato: camila@desa.ufmg.br
}

\begin{abstract}
The use of permeable reactive barriers (PRB) has been drawing the attention of researchers for groundwater contaminations. Searching for a new material capable to reduce hexavalent chromium, this work proposes the application of a steel waste (BFD) as reactive media to reduce and precipitate chromium in loco. Batch tests wore developed in order to check the applicability of the residue on the reduction process. Results of batch tests showed that BFD can reduce up to $60 \%$ of hexavalent chromium on solution.
\end{abstract}

\section{INTRODUCTION}

Natural occurring due to rocks composition, or wrongly disposed from industrial activities, hexavalent chromium is a important problem on groundwater, and deserves attention because is carcinogenic according to International Agency for Research on Cancer (IARC, 1990). Although hexavalent chromium represents a risk, trivalent chromium is an atoxic micronutrient, and a less mobile compost due to its capacity to form insoluble hydroxides. Environmentally speaking reduce $\mathrm{Cr}$ VI to $\mathrm{Cr}$ III is a great remediation for groundwater.

Remediation technologies for groundwater usually involve pump water, treat it outside of soil and then pump the water again to soil. The pump \& treat technologies requires a large amount of power and high cost. Looking forward for alternative techniques, permeable reactive barriers (PRB) has been drawing the attention of researchers because of the facility and low operational (EPA, 1998). The technique consist in introduce a reactive media in the soil, perpendicularly to the groundwater flow, expecting the reaction (contaminant degradation, precipitation and sorption) of this material with the present contaminants (THIRUVENKATACHARI, 2007) as can be observed on Figure 1. 


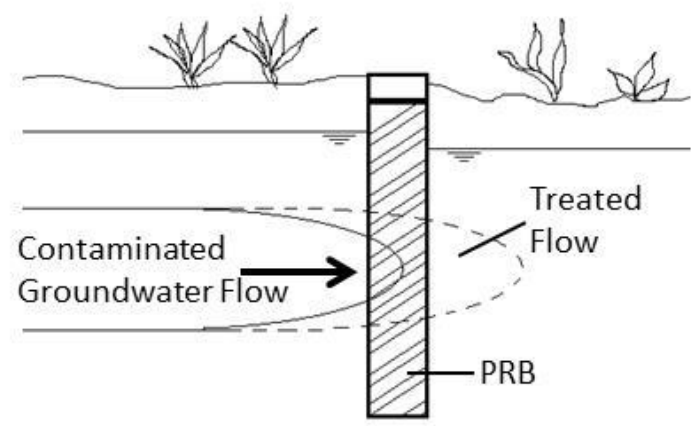

Figure 1 - Schematic system for a permeable reactive barrier. Adapted from Gavaskar (2000).

In the case of hexavalent chromium remediation, PRB systems can be used introducing a reactive media capable to reduce Cr VI to Cr III. Thiruvenkatachari (2007) studied 124 PRB projects in US, and related that $45 \%$ of those projects proposes iron as reactive media.

For chromium reduction, iron can react as showed in Equations 1 and 2 (EPA, 1998; BLOWES, 1997):

$$
\begin{aligned}
& \mathrm{CrO}_{4}^{2-}+\mathrm{Fe}^{0}+8 \mathrm{H}^{+} \rightarrow \mathrm{Fe}^{3+}+\mathrm{Cr}^{3+}+4 \mathrm{H}_{2} \mathrm{O} \\
& \mathrm{Cr}^{6+}+3 \mathrm{Fe}^{2+} \rightarrow 3 \mathrm{Fe}^{3+}+\mathrm{Cr}^{3}
\end{aligned}
$$

The PRB construction can involve the use of hundreds tons of reactive media, and this factor can prohibit economically the use of several studied compounds that technically showed good results.

Looking for alternative reactive media, this work proposes the use of a steel waste, rich in iron and carbon. According to the Sustainability Report of Brazil Steel Institute (2013), the country has generated the amount of 17.1 million tons of steelmaking wastes in $2012.11 \%$ of these wastes can't return to the process due to its chemical characteristics or particle size distribution, being stocked or destined to landfill. Among these steelmaking wastes, we can find the Blast Furnace Dust (BFD), that presents a high percentage of iron in its composition, and showed good results for $\mathrm{Cr}(\mathrm{VI})$ reduction (AMORIM, 2013) in batch systems.

\section{METHODOLOGY}

For the characterization were realized the following analyses: ray-x diffraction (Diffractometer, model PW1710, CuK a = $1.54051 \AA$; graphite crystal monochromator, scan rate of $\left.0,06^{\circ} 2 \theta / \mathrm{s}\right)$, that was held for the identification of the iron crystalline stages present on BFD. For the identification and quantification of the stages of presents iron on residue, was used the Mossbauer spectroscopy technique (57CO font in Rh matrix, using $\alpha-\mathrm{Fe}$ as standard).

The batch tests, were held in flasks, where were added $5 \mathrm{~g}$ of samples of steel waste in suspension in $50 \mathrm{ml}$ of a $\mathrm{K}_{2} \mathrm{Cr}_{2} \mathrm{O}_{7}$ solution with a concentration of $50 \mathrm{mg} / \mathrm{L}$ of $\mathrm{Cr}(\mathrm{VI})$. Samples were analyzed for the presence of $\mathrm{Cr}(\mathrm{VI})$ by the colorimetric method of diphenylcarbazide. The 1.5- 
diphenylcarbazide reagent, complex with hexavalent chromium in acidic $\mathrm{pH}$, forming a solution which can be measured by visible spectrophotometry $(540 \mathrm{~nm})$ (spectrophotometer UV - 1650 PC, Shimadzu).

In order to check if a previous acid washing was necessary, we performed a batch test on three different pretreatments:

1) 5 grams of BFD washed with acid solution $(3 \mathrm{M}), \mathrm{pH}$ of reaction was $6.8 \rightarrow 10 \mathrm{~mL}$ of $\mathrm{HCl}$ was added, and after the agitating, the solution was discarded, and the residue was washed with $20 \mathrm{ml}$ of deionized water by 3 consecutive times. On second rinse the $\mathrm{pH}$ was raised to 7 to avoid possible interference of low $\mathrm{pH}$ on the reduction of $\mathrm{Cr}(\mathrm{VI})$

2) 5 grams of BFD washed with acid solution $(3 \mathrm{M})$, $\mathrm{pH}$ of reaction was $2.8 \rightarrow 10 \mathrm{~mL}$ of $\mathrm{HCl}$ was added, and after the agitating, the solution was discarded, and the residue was washed with $20 \mathrm{ml}$ of deionized water by 3 consecutive times, with no $\mathrm{pH}$ adjustments.

3) 5 grams of BFD washed with water $(3 \mathrm{M})$, $\mathrm{pH}$ of reaction was $7 \rightarrow$ The residue was washed with deionized water and no $\mathrm{pH}$ adjustment.

\section{RESULTS}

\section{1. $\quad$ Steelmaking Waste Characterization}

According to the preliminary characterization by Amorim (2013), presented on Table 1, it's possible to note that the residue used has a superficial area relative low. It is a very thin powder, with predominance of mesopores and has an elevated zero charge point (zcp).

Table 1-Characterization of BFD (AMORIM et al, 2013)

\begin{tabular}{cc}
\hline \multicolumn{2}{c}{ Steelmaking waste BFD } \\
\hline Parameter & Values \\
\hline Area $(\mathrm{BET})\left(\mathrm{m}^{2} \cdot \mathrm{g}^{-1}\right)$ & 3.4 \\
Total pore volume $\left(\mathrm{cm}^{3} \cdot \mathrm{g}^{-1}\right)$ & $1.11 \times 10^{-3}$ \\
Pore diameter $(\mathrm{nm})$ & 13.2 \\
Particles size & $99.6 \%<75 \mu \mathrm{m}$ \\
$\mathrm{pH} z \mathrm{zp}$ & 10 \\
X-ray fluorescence & $\mathrm{Fe}, \mathrm{O}$ \\
-Majoritarian elements: & $\mathrm{Si}, \mathrm{Al}, \mathrm{S}, \mathrm{P}, \mathrm{Mg}$ \\
-Minoritarian elements: & $\mathrm{Mn}, \mathrm{Cr}, \mathrm{Ti}, \mathrm{V}, \mathrm{Ca}, \mathrm{K}, \mathrm{Cl}, \mathrm{Na}$ \\
\hline
\end{tabular}


X-ray diffraction analysis of the BFD waste (Figure 2) indicated the presence of hematite $\alpha$ Fe2O3 $\left(2 \theta\right.$ at $\left.28.2,38.8,41.8,48.0,58.3,63.9,74.0,76.2^{\circ}\right)$ and a spinel structure $(2 \theta$ at 20.8, 35.3, $40.9,42.7,50.03,62.4,66.4,73.3^{\circ}$ ) related to the presence of $\mathrm{Fe}_{3} \mathrm{O}_{4}$ magnetite.

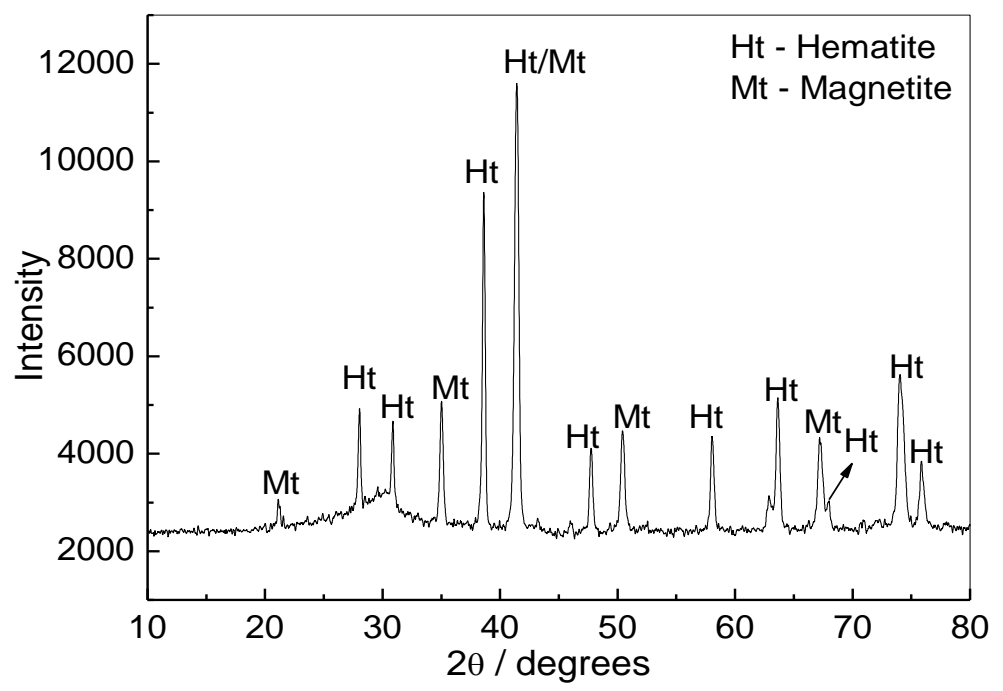

Figure 2 - Powder X-ray diffraction of BFD ( $\mathrm{Ht}=$ hematite and $\mathrm{Mt}=$ Magnetite).

The results of the iron species distribution by Mössbauer analysis indicated the presence of maghemite $(7 \%)$, hematite $(51 \%)$ and magnetite $(42 \%)$, with tetrahedral site $\left[\mathrm{Fe}_{3} \mathrm{O}_{4}\right]$ and octahedral sites $\left\{\mathrm{Fe}_{3} \mathrm{O}_{4}\right\}$ (Figure 3).

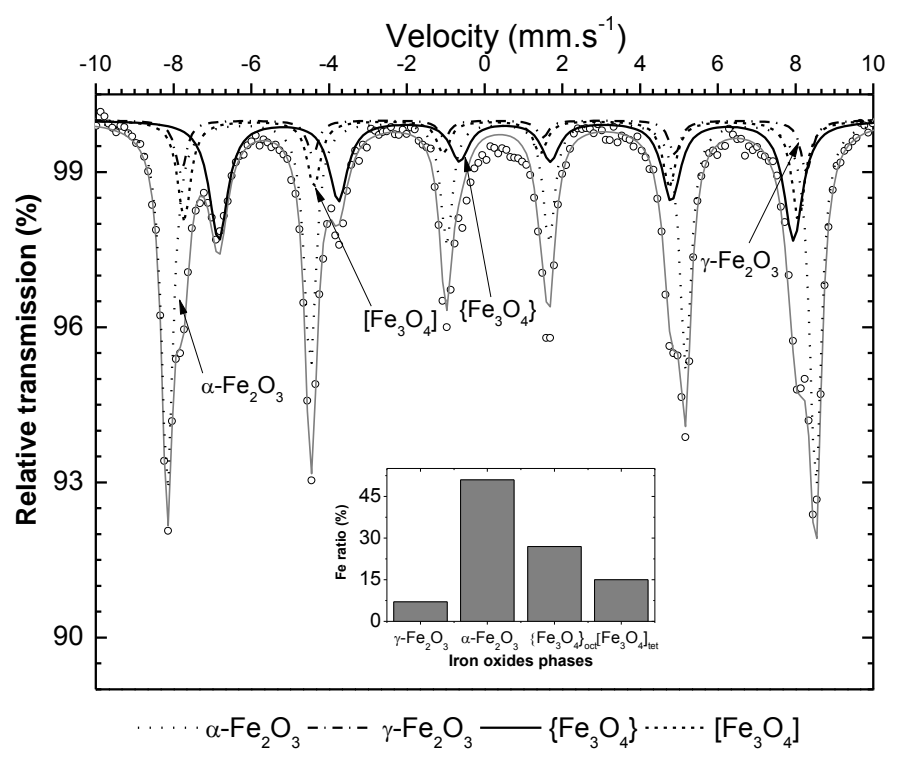

Figure 3 - Mössbauer spectra and iron phase distribution for BFD. 
As can be observed on mössbauer spectra, around 50\% of the iron from this steel waste can be considered magnetic. For the proposal of this study, BFD is an interesting material due to the high amounts of iron. As shoed on X-ray and Mössbauer spectra, the iron present on the steel waste is Fe II and Fe III. The first one can reduce hexavalent chromium, as showed on Equation 2.

\subsection{Batch Tests}

Several studies indicate that acid washing from iron eliminates the presence of a possible oxidized layer, exposing the most reactive materials and providing greater effectiveness in reducing process (THIRUVENKATACHARI, 2007; MAGALHÃES, 2012). Due to this, previous tests were performed to decide if acid washing was necessary.

Three batch tests were realized to compare the following conditions: water washing (washed with water, and reactional $\mathrm{pH}=7$ ); acid washing (washed with acid, and reactional $\mathrm{pH}=6.8$ ) and acid washing (washed with acid, and reactional $\mathrm{pH}=2.8$ ). The results from of these preliminary tests can be observed at Figure 4.

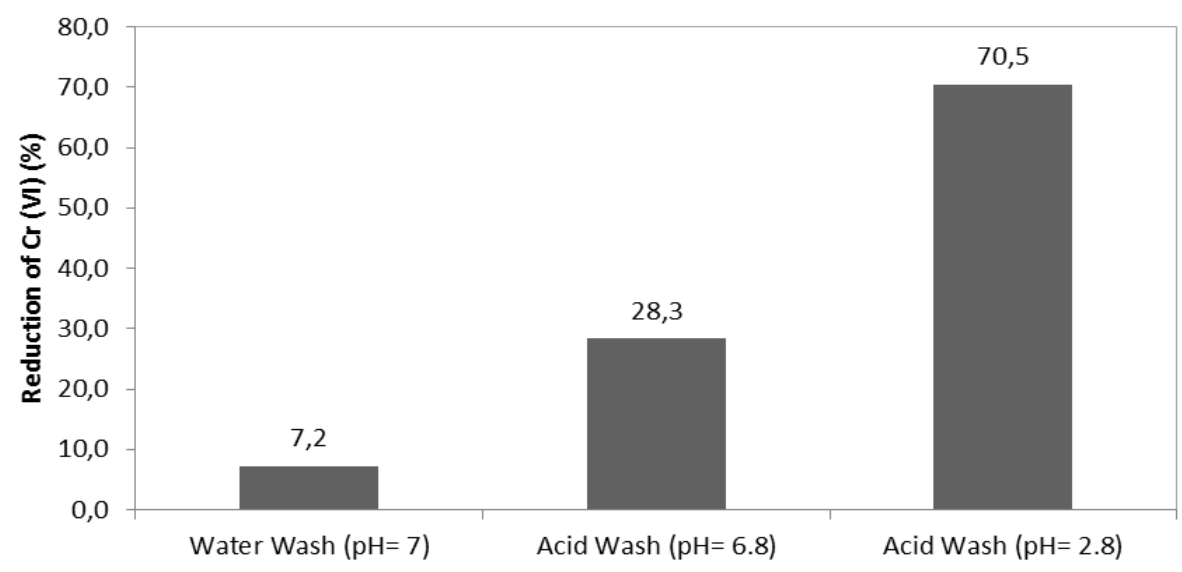

Figure 4 - Results from previous tests comparing different pretreatments to BFD.

Previous acid wash showed to be an interesting way to improve BFD capacity to reduce hexavalent chromium. As can be observed, the $\mathrm{pH}$ value during the test also interferes, and acid wash plus low $\mathrm{pH}$ values can reduce up to $70 \%$ of chromium in solution.

Figure 5 presents the reduction process during the time, at the best operational conditions (acid wash and $\mathrm{pH}=2.8$ ). 


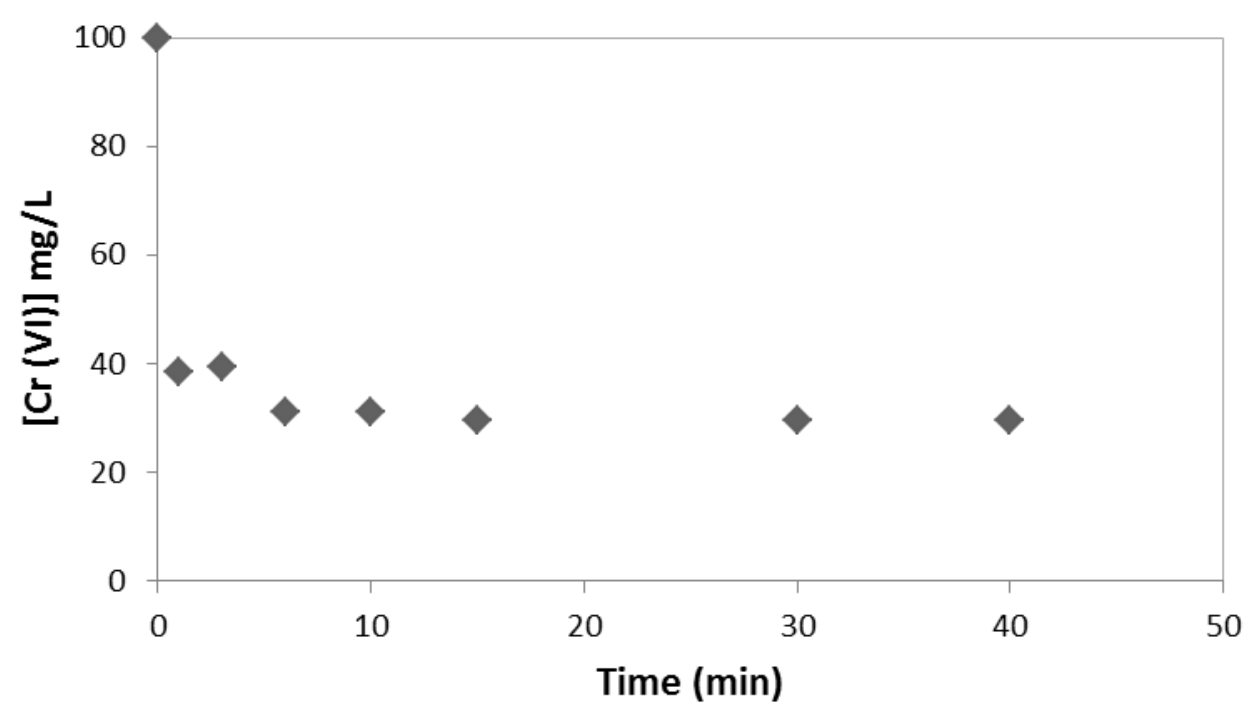

Figure 5 - Hexavalent chromium reduction during the time using BFD at $\mathrm{pH}=2.7$ (washed with acid medium).

Result of Figure 5 show that reaction occurs at the first minutes, that the process is capable to reduce $70 \%$ of the $\mathrm{Cr}(\mathrm{VI})$ on solution, and that each gram of BFD can reduce $0,3 \mathrm{mg}$ of $\mathrm{Cr}$ (VI).

According to the results, BFD can be used as a reactive media to reduce hexavalent chromium in PRBs systems. The mechanism that reduces $\mathrm{Cr}$ (VI) is described at Figure 6. As showed, $\mathrm{Cr}$ (VI) reacts with $\mathrm{Fe} 2+$ from the steel waste, oxidizing it to $\mathrm{Fe} 3+$. The trivalent chromium formed can react with $\mathrm{Fe} 3+$ and adsorb or precipitate.

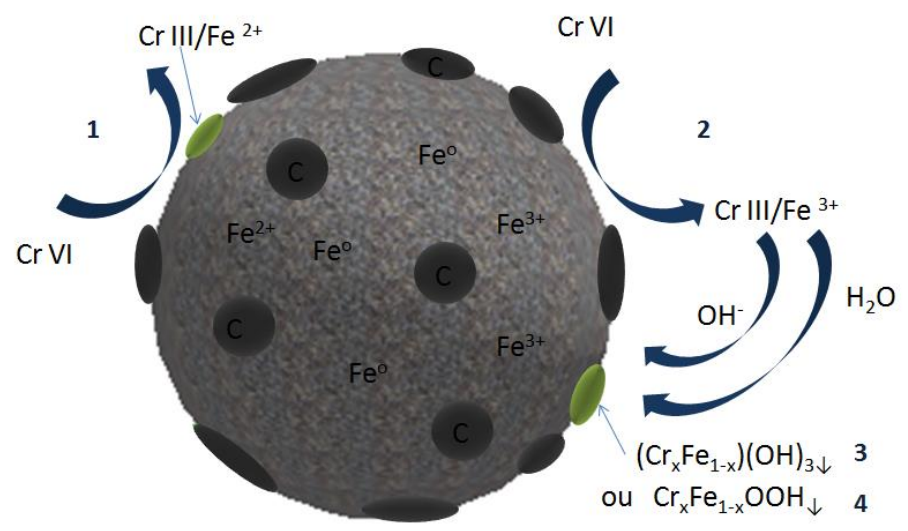

Figure 6 - Mechanism proposed for hexavalent chromium reduction using BFD as reductor agent. 


\section{CONCLUSIONS}

The presented research shows us that Blast Furnace Dust has a capacity to reduce hexavalent chromium. More research is needed to define specific parameters for the use of this residue as reactive media on PRB systems, but the implementation of the proposed system associates the destination of a stocked waste, and a cut of cost on a groundwater remediation technology.

\section{ACKNOWLEDGEMENT}

The authors thank the Foundation for Research Support of the State of Minas Gerais - FAPEMIG and CNPQ for the financial support, and also the chemical analysis laboratory of the department of metallurgical engineering from the Federal University of Minas Gerais.

\section{REFERÊNCIAS}

AMORIM, C. C.; LEÃO, M. M D.; MOREIRA, R. F. P . M.; FABRIS, J. D.; HENRIQUES, A.B. Performance of Blast Furnace Wasre dor Azo Dye Degradation Through Photo-Fenton-Like Process. Chemical Engineering Journal, v. 224, p.59-66, 2013.

BLOWES, D. W.; PTACEK, C.J.; JAMBOR, J. L. In-Situ Remediation of Cr(VI)- Contaminated Groundwater Using Permeable Reactive Wals: Laboratory Studies. Environmental Science \& Technology, v. 31, n.12, p. 3348-3357, 1997.

IARC. Chromium, nickel and welding. IARC Monographs on the Evaluation of Carcinogenic Risks to Humans, v. 49, p. 1-648, 1990

INSTITUTO AÇO BRASIL. Sustainability Report 2013. Available in:< http://www.acobrasil.org.br/site/portugues/sustentabilidade/relatorio.asp>. Access in: April 17 of 2014.

MAGALHÃES, F.; PEREIRA, M. C.; FABRIS, J. D.; BOTTREL, S. E. C.; SANSIVIERO, M. T. C.; AMAYA, A.; TANCREDI, N.; LAGO, R. M. Novel highly reactive and regenerable carbon/iron composites prepared from tar and hematite for reduction of $\mathrm{Cr}(\mathrm{VI})$ contaminant. Chemical Engineering Journal, v. 209, p. 645-651, 2012.

U.S.EPA- RTDF. Permeable Reactive Barrier Technologies for Contaminant Remediation, 1998.

THIRUVENKATACHARI, R.; VIGNESWARAN, S.; NAIDU, R. Permeable Reactive Barrier for Groundwater Remediation. Journal of Industrial and Engineering Chemistry, vol 14. p 145-156, 2008.

GAVASKAR, A.; GUPTA, N.; SASS, B.; JANOSY, R.; HICKS, J. Design Guidance for Application of Permeable Reactive Barriers for Grounwater Remediation. United States Department of Defenses's. Public Report, 2000. 